\title{
APPLICATION OF THREE - DIMENSIONAL SOLID MODELING OF VIRTUAL REALITY TECHNOLOGY IN SHIP ASSEMBLING
}

\author{
Ying Wang \\ School of Marine and Marine Engineering, Jiangsu Maritime Vocational and Technical College, \\ Nanjing, Jiangsu, 211107, China \\ email: wangying12@yahoo.com
}

\begin{abstract}
With the development of science and technology, virtual reality technology as a new technology has been applied to more and more areas. In the traditional shipbuilding industry, the shipbuilding period is usually long and frontline workers tend to make mistakes because of negligence of small details while making ship fitting according to the two - dimensional drawing of the ocean designer. In this study, virtual reality technology is applied to build a three - dimensional solid model in order to realize a vivid expression of the ship model and its assembly process. Compared with the traditional abstract drawing, the three-dimensional solid model allows designers and shipbuilders to be more unified, avoids wasting of resources in the construction process and makes it more convenient for the frontline workers to operate in reality, so as to improve the shipbuilding efficiency and shorten the shipbuilding cycle.
\end{abstract}

Keywords: virtual reality technology, ship assembling; 3D model, digital shipbuilding.

\section{Introduction}

With the development of international maritime trade, competition gradually appears in the shipbuilding industry. In order to enhance their own competitiveness, the major shipbuilding enterprises are gradually applying digital technology to shipbuilding [1-2]. South Korea and Japan are countries that early applied the technology of digital shipbuilding. Although China's shipbuilding technology has a long history, there exist many problems compared with other countries. In China's traditional shipbuilding mode, front-line assemblers often have problems in assembling due to a lack of professional training on three-dimensional views, which leads to waste of manpower and material resources, extension of the shipbuilding cycle, overcapacity, delivery difficulties and other problems [3-4]. Qu S et al. [5] applied the Memetic algorithm to the assembly line in shipbuilding and improved work efficiency. Liu Zhuo et al. [6] used discrete events to simulate prospectiveness and demonstrated the simulation in the local shipyard in order to achieve the shipyard assembling using scheduling blocks, accurately predict the required space resources and carry out effective production control. Shafiee et al. [7] established a new costeffective automation system based on the current shipbuilding process and tested its feasibility, which showed that the system was conducive to the further development of the shipbuilding technology.
The digital ship assembling concept proposed in this paper takes digital modelling as the main content, which integrates the information technology, the digital manufacturing technology and the modern shipbuilding mode. In recent years, the study of digital shipbuilding technologies has made great progress, of which the virtual reality technology is the most important one. Based on the virtual reality technology, this paper establishes a threedimensional solid model to express the ship model and its assembling process in three dimensions. The study found that virtual reality technology could make the ship assembling design more threedimensional and make it easier for staffs to operate, which improved shipbuilding efficiency and shortened the shipbuilding cycle.

\section{Concept and Application of Virtual Reality Technology}

\subsection{The concept of virtual reality}

Proposed by the US VPL research firm, virtual reality technology is a product of the combination of computer, microelectronics, simulation and measurement sensors and other advanced technologies. By constructing a same or very similar environment as the real world on the computer, people communicate in a virtual environment through virtual devices. The virtual reality system consists of virtual engine, input and output device, software and database, user and task. 
The virtual engine and I / 0 device are the core of virtual reality system. The structure of the virtual reality system is shown in Fig. 1.

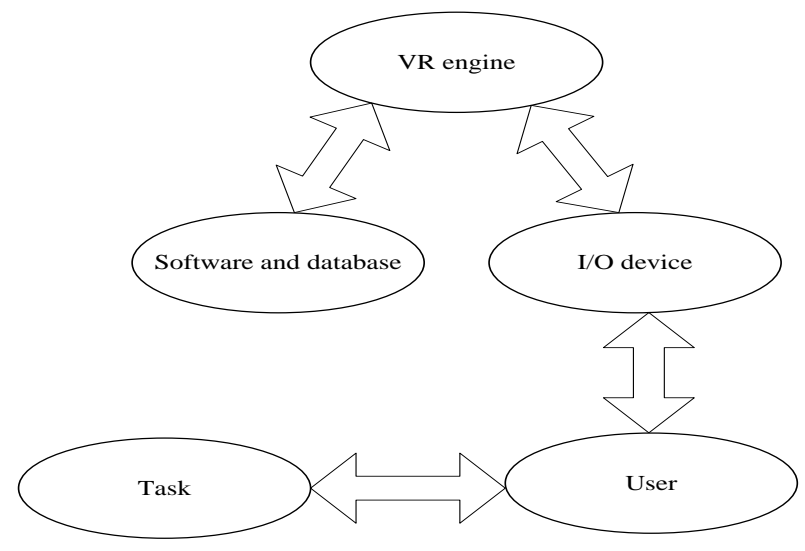

Figure 1: Constituent Parts of the Virtual Reality System

\subsection{The application of virtual reality}

The application of virtual reality technology in engineering is mainly embodied in the design of product appearance and the optimization of product assembling. Product appearance design includes design-centric virtual manufacturing technology, production-centric virtual manufacturing technology and control-centric virtual manufacturing technology. Virtual reality system is mainly used to build the three-dimensional model, physical model and motion model of objects in virtual environment, generate three-dimensional virtual stereo technology, virtual environment management technology, real-time display technology and establish the three-dimensional model database.
The design of the traditional hull model is started by manual design, which then gradually developed from computer design to today's three-dimensional simulation design. The $3 \mathrm{D}$ solid model is a combination of virtual roaming and virtual simulation. The commonly used modelling method is 3DS Max modelling method [8].

\section{Ship Assembling Digital Technology}

The hull is a complex structure. In the shipbuilding process, the assembling technology is applied in almost a half of the entire shipbuilding process and is the key factor to determine the shipbuilding cycle. Rework can be caused at every stage of the ship assembling process due to unreasonable production design and assembling sequence errors, which will result in the extension of the shipbuilding cycle and a serious waste of manpower and resources. The shortage of resources and increased competition is an important disadvantage in the development of today's shipbuilding industry. In this paper, ship assembling is modelled by Tribon software and 3DS Max modelling method to digitally present the complete three-dimensional geometric information in the three-dimensional model. At the same time, the inter-entity constraints, interconnection, and non-geometric information are achieved. Compared with the traditional shipbuilding model, virtual reality technology can greatly shorten the shipbuilding cycle, reduce shipbuilding costs, bringing a breakthrough for the assembling technology of the shipbuilding industry. Table 1 compares traditional shipbuilding technology with 3D solid shipbuilding technology.

Table 1. Comparison between the traditional shipbuilding technology and the 3D solid shipbuilding technology

\begin{tabular}{|l|l|l|l|}
\hline $\begin{array}{l}\text { Traditional } \\
\text { shipbuilding } \\
\text { technology }\end{array}$ & $\begin{array}{l}\text { Presentation } \\
\text { mode, with little design } \\
\text { and manufacturing } \\
\text { information contained. }\end{array}$ & $\begin{array}{l}\text { Details need to be } \\
\text { further discussed } \\
\text { between the } \\
\text { designer and the } \\
\text { staffs. }\end{array}$ & $\begin{array}{l}\text { Complex } \\
\text { design, with } \\
\text { long } \\
\text { shipbuilding } \\
\text { cycle. }\end{array}$ \\
\hline $\begin{array}{l}\text { 3D solid shipbuilding } \\
\text { technology }\end{array}$ & $\begin{array}{l}\text { Presented in 3D solid } \\
\text { mode, containing a lot of } \\
\text { 3D geometric information. }\end{array}$ & $\begin{array}{l}\text { With the 3D } \\
\text { model, the details } \\
\text { are apparent and } \\
\text { easy to be } \\
\text { understood. }\end{array}$ & $\begin{array}{l}\text { Simple design, } \\
\text { shith } \\
\text { short } \\
\text { cycle. }\end{array}$ \\
\hline
\end{tabular}




\section{Construction of Three- dimensional Solid Model of Ship hull}

This modelling uses 3DS Max modelling software, which realizes modelling through direct modelling and modelling based on the model data transferred by ready-made data. Before modelling, the staffs need to learn about the design drawings of the ship, the structure of the ship, the locations of equipment and the positional relationship between the equipment. 3DS-Max's modelling tools, on the one hand, offer a very wide range of polygon modelling tool components and, on the other hand, provide Nurbs patch modelling tool components.

The modelling based on 3DS Max software generally includes bar line modelling and polygon modelling. In this paper, conditional modelling is carried out on the ribs of the vessel, curve modelling is carried out on the outer panel of the hook surface and polygon modelling is carried out on the upper structure [9]. This paper mainly deals with the subdivision of a 12000DWT heavy lift ship. The ship assembling and modelling is completed through the conversion of the model data from the Tribon system to the 3DS Max $\rightarrow$ VR-Platform. The heavy lift ship is divided into the bottom part, side part, bow part and stern part, and the bottom of the ship is made up by the inner and outer bottom plates, rib plates, longitudinal plates, girders and stiffeners. The following figure shows models of the girders and ribs.
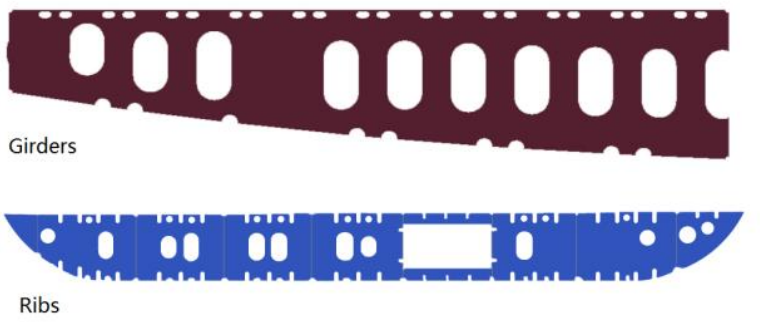

Figure 2: Model diagram of girders and ribs

\section{Assembling of ship model in virtual environment}

The assembling of a ship model in a virtual environment is an assembling process of the ship on a simulation platform through the computer. Ship assembling is a process that assembles a ship by various components, which can be divided into part assembling, subsection assembling, block assembling and shipway assembling [10]. The virtual assembling of the heavy hull is divided into bottom assembling, side assembling and bow assembling based on the division of different parts of the heavy lift vessel.

\subsection{Bottom assembling}

Compared with other vessels, the bottom of the heavy lift is a double bottom structure to enhance the ship's anti-sink capacity and its safety in operation. In the assembling process, the jig frame needs to be prepared and the outer baseboard needs to be installed first. Alignment is required based on the designed water lines and inspection ribs. Then, the distance and position of the vertical and horizontal frame is measured to keep the interval the same. After the framework is welded, the inner baseboard is installed, followed by ring installation and strengthening, division of horizontal lines, segment center lines and ribs, segmentation of jig frames, etc. In the design of the rib plate, the main components of the watertight and non-watertight fins are flat plates. In the installation of the rib plate, firstly, the uninterrupted outer plate longitudinals and intermittent side trusses are installed; then, the ribs are inserted and the middle truss is inserted into the ribs. Figure 2 shows the model of the truss and the rib.

\subsection{Side assembling}

The structure of the side section includes the outboard, rib, side girders. The mounting of the side is carried out according to different line styles. When the line is straight or parallel in the body area, direct assembling and welding is carried out. When the line is a curve with a large curvature, assembling and welding is firstly carried out on the bed-jig, followed by whole assembling. The installation methods of the above two situations are basically the same.

Firstly, outer board assembling is carried out, with the vertical and horizontal frame line divided. According to the design of the waterline, segmentation of the side is carried out. Then, ribs are installed. Since the side rib design is constrained by the outer plate shape, it is necessary to obtain the mapping curve of the side rib on the side outer plate through surface intersection to generate the web profile sketch. Then, stretch is performed according to the thickness of the web to generate a web body. Then, use a similar method to generate panels. After installation of the ribs, the side girders and strong ribs are welded. The assembling of side girders is performed by suiting them on common ribs which are connected with strong ribs. During positioning, a horizontal ruler or angle template are used to check its angle with the outer plate, which needs to be fixed and supported. After the assembling, sub-lifting and turning over is performed to facilitate the outer seam welding. At the same time, the design waterline is leaded to the outer surface of the outer panel and the ribbed line of the test is marked. Finally, completion measurement and acceptance is required. 


\subsection{Bow assembling}

In addition to the bottom and side assembling, deck assembling is also included. Due to the differences of structural form and lifting capacity, the bow is divided into several small segments, which is then assembled to a bow three-dimensional segmentation based on the sequence of bottom assembling, side assembling and deck assembling. The specific assembling order of the bow is shown in Figure 3 and the finally formed assembling model is shown in Figure 4.

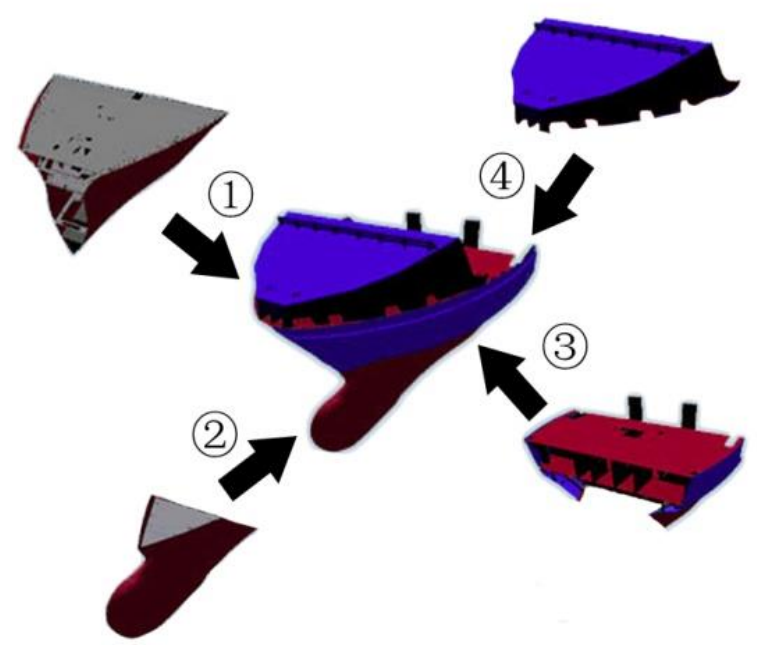

Figure 3: Assembling diagram of the bow

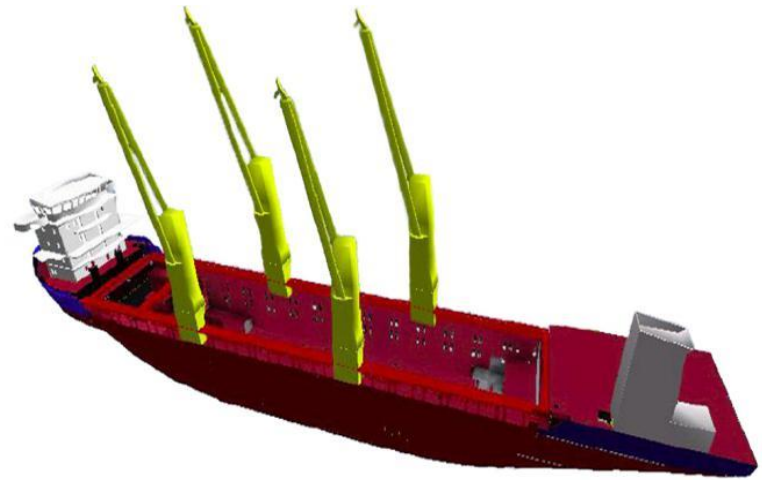

Figure 4: Final assembling model

\section{Simulation design of the hull virtual assembling}

\section{a. Assembling process}

First of all, carefully study the design of the ship assembling drawings, so that a full understanding of the inner structure of the ship is obtained. Next, modelling is carried out in the Tribon software. Besides, the ship models completed by the software must be leaded into the 3DS-Max software for postoptimization on material texture, texture lighting, etc. After the model is imported, the hull can be modelled by human-computer interaction and assembling demonstration functions. The modelling process is shown in figure 5.

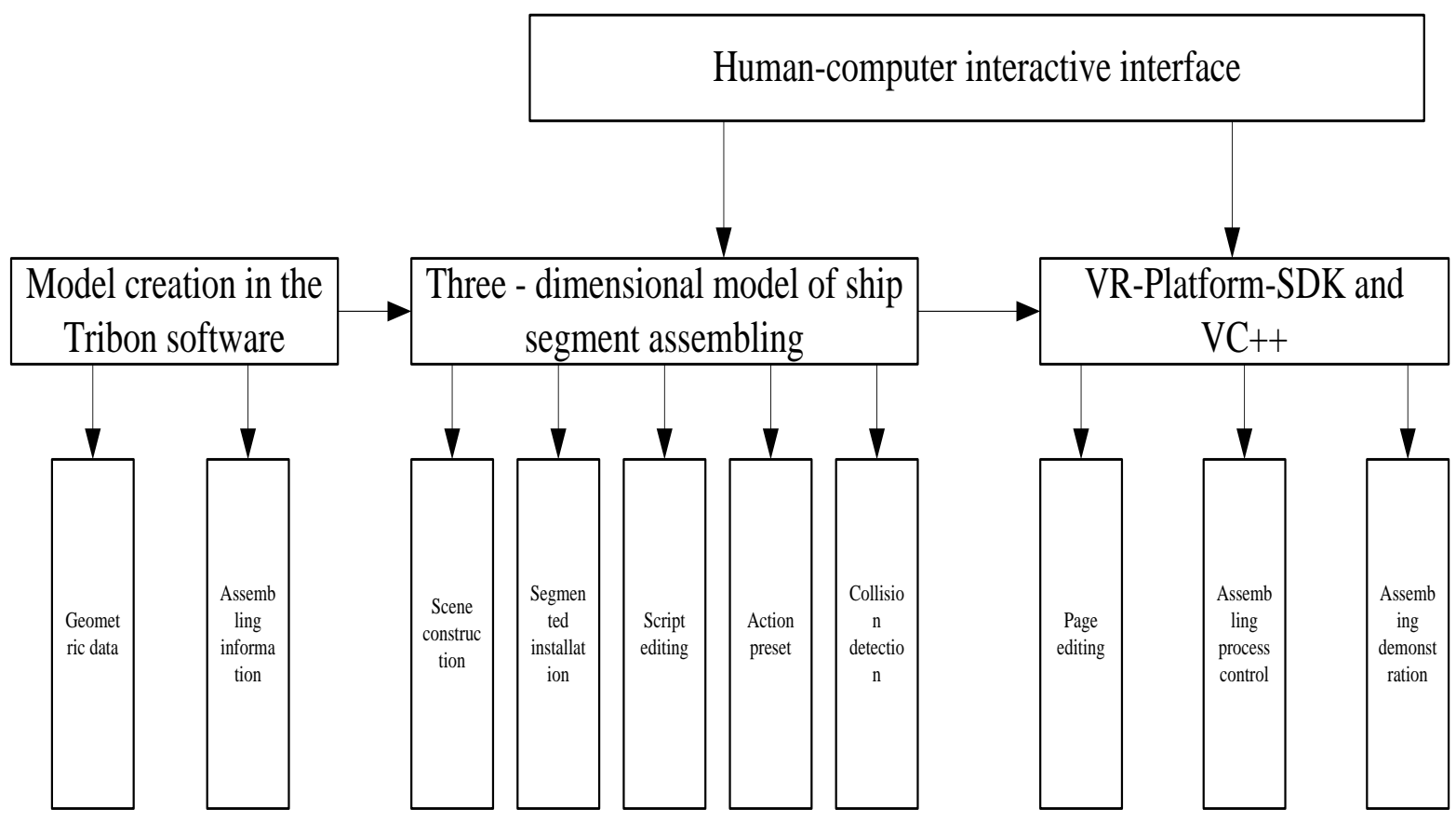

Figure 5: The modelling process 


\section{b. 3D virtual scene}

In the construction of a 3D virtual scene, first comes the 3D modelling work of a selected scene. Using the completed ship three-dimensional model, the virtual assembling animation settings are completed in the 3DS-Max. Then, the model is leaded into the VR-Platform for material optimization. Material properties processing, multi-layer mapping settings and color adjustment are carried out on the completed models; Action is controlled by mouse events. Use the script editor to edit the script function to implement the mouse event. Finally, by creating a new panel, setting the functions of the switches and buttons, interface and animation control are realized. After the VR-Platform 3D model has been processed, its platform interface is embedded in the Visual C ++ application. By programming, simulation interface editing and assembling animation process control are achieved.

\section{c. Assembling virtual simulation script code control}

Firstly, instructions are sent to the virtual environment by pressing the button. Then, the system writes program scripts, and the control script code is as follows:

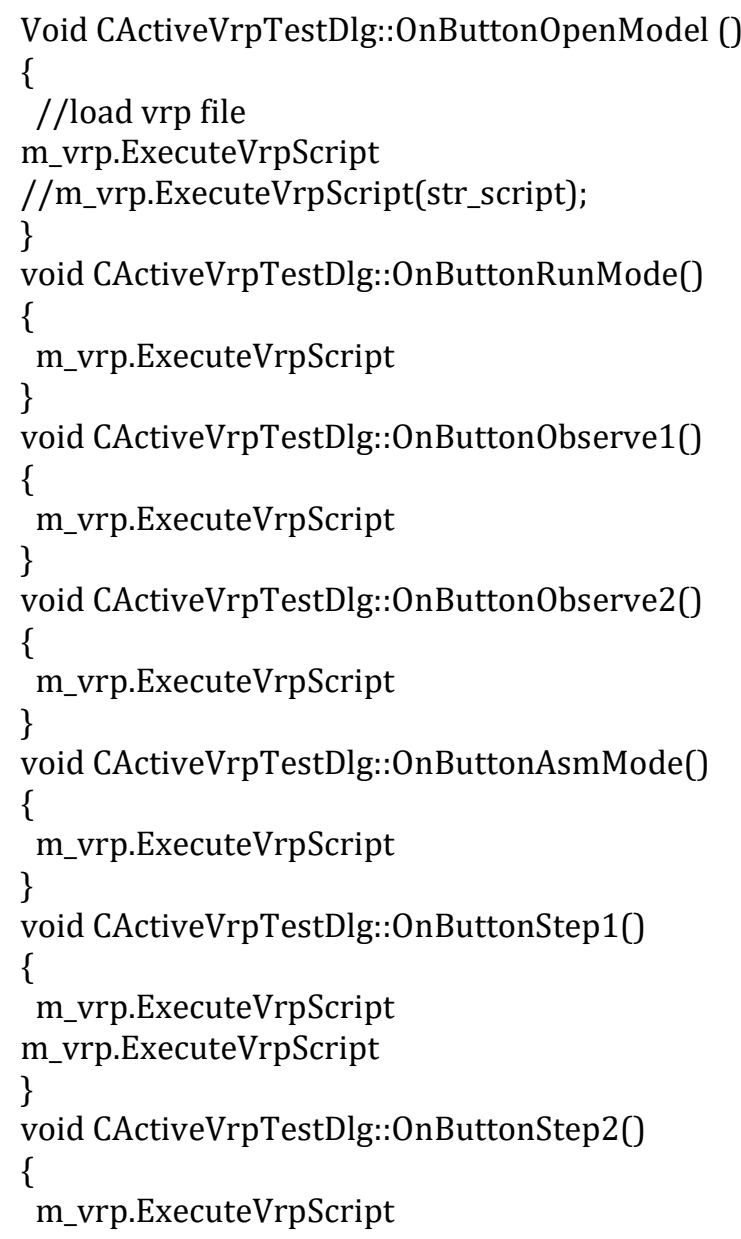

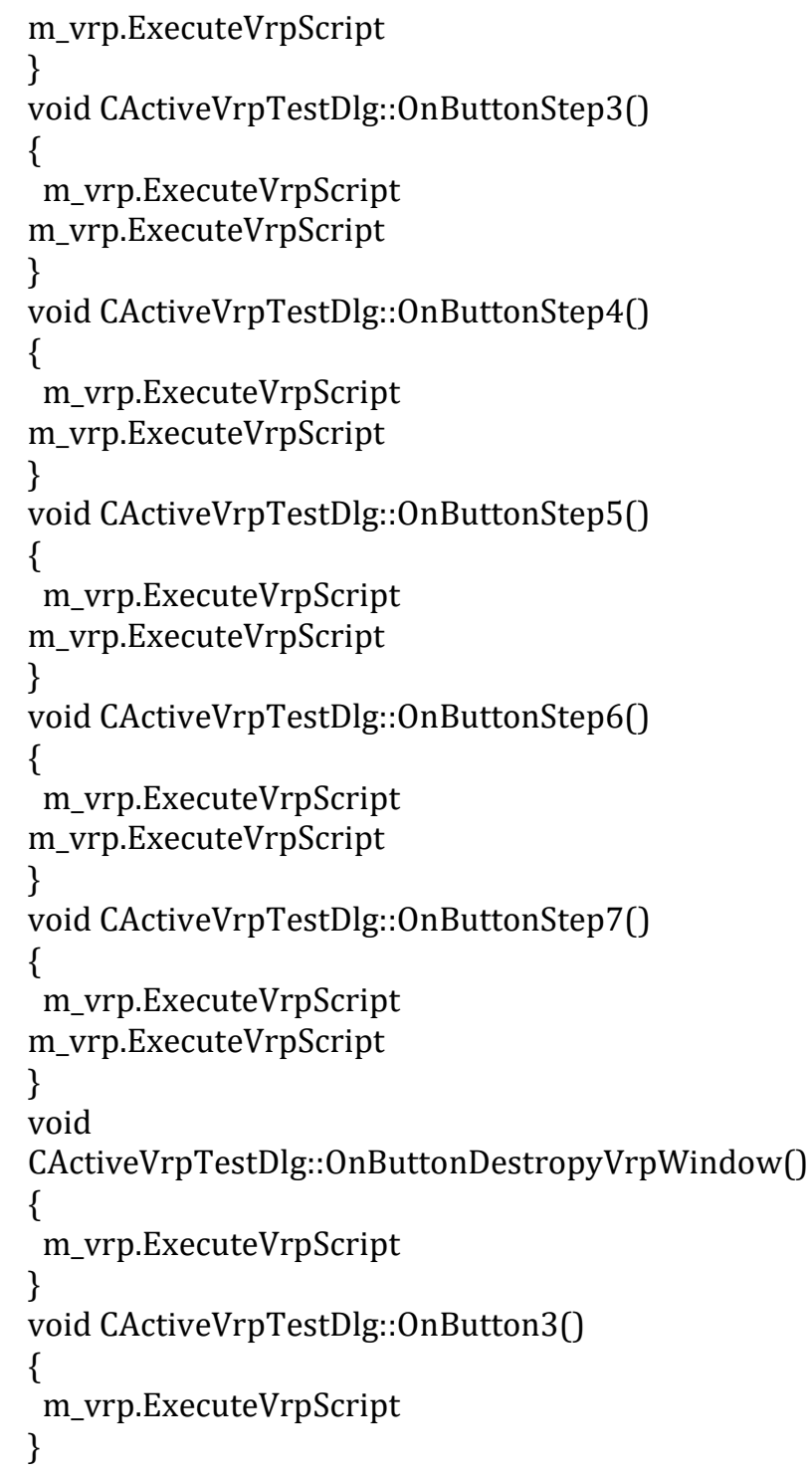

\section{Discussion and Conclusion}

Ship assembling is a large and complex project as well as the basis of shipbuilding. With the continuous improvement of science and technology, China's shipbuilding industry and its assembling technology have been further developed and improved. There are many factors which influence the assembling process, such as the professional level and technical proficiency of workers and the rational allocation of human resources. Construction assembling and segment assembling are important links which affect the process level and efficiency of the whole assembling [11] process.

Digital shipbuilding technology designs, manufactures, tests, manages, and maintains ships at every stage of shipbuilding through information technology, digital manufacturing technology, and shipbuilding technology. In recent years, digital shipbuilding technology has played an important role in improving quality, reducing costs and 
shortening lead times, whether it is a civilian ship or a military ship [12-13]. In this paper, a threedimensional ship model is established in the virtual environment, according to which the workers can assemble the ship, which avoids mistakes and ensures accuracy in the real operations. Lee D M et al. [14] argued that although the use of block construction in shipbuilding had a high efficiency, there were many problems. Thus, they proposed a 3D VAS measurement system based on virtual assembling system, and proved that the method was effective. Lee H D et al. [15] proposed an automated system similar to a hull module and performed a batch update of the database tables.

Taking the heavy lift vessel as an example, this paper uses the virtual reality technology to build the $3 \mathrm{D}$ model [16] in the virtual environment and carries out the assembling. The results of this study showed that the efficiency of the assembling was greatly improved and the quality was better, indicating that the technology had a good effect on the assembling of ships. In order to take the lead in the future development of marine resources, countries compete with each other, with a large number of research and development technologies invested into the shipbuilding industry. Although China has made great progress in this regard, a significant gap still exists, compared with the world shipbuilding powers. Therefore, it is necessary for China to increase the application of information technology to achieve digital shipbuilding. In conclusion, the virtual reality technology makes it more convenient for the frontline workers to operate in reality, so as to improve the shipbuilding efficiency and shorten the shipbuilding cycle.

\section{References}

[1] Levering R, Ligthart R, Noorderhaven N, et al. Continuity and change in interorganizational project practices: The Dutch shipbuilding industry, 1950-2010[J]. International Journal of Project Management, 2013, 31(5):735-747.

[2] Deng Z J, Song S Y, Li J W. Summary of the Basic Research of Digital Shipbuilding [J]. Advanced Materials Research, 2014, 912-914(912914):1420-1422.

[3] Koo J. A Comparative Analysis on the Competitiveness of the Shipbuilding Industries of Korea and Japan [J]. 2015, 11(3):251-266.

[4] Chen Shaorui. Discussion on China's shipbuilding industry information problems and measures [J]. China Science and Technology Expo, 2014 (34): 373-373.
[5] Qu S, Jiang Z. A memetic algorithm approach for batch-model assembly line balancing problem of sub-block in shipbuilding [J]. Proceedings of the Institution of Mechanical Engineers Part B Journal of Engineering Manufacture, 2014, 228(10):1290-1304.

[6] Liu Zhuo, David Chua Kim Huat, Keng Hwee Wee. Scheduling dynamic block assembly in shipbuilding through hybrid simulation and spatial optimisation [J]. International Journal of Production Research, 2012, 50(20):1-19.

[7] Shafiee K, Pan Z X, Van Duin S, Larkin N.Automated Assembly of Ship Panels Using an Integrated Robotic Tool [J]. Advanced Materials Research, 2011, 338(338):639-644.

[8] Komura T, Lau R W H, Lin M C, et al. Virtual Reality Software and Technology [J]. IEEE Computer Graphics \& Applications, 2015, 35(5):20-21.

[9] Attila S, Adam B, Robert K. Surface models view designs with 3DS MAX software[C]// IEEE, International Conference on Computational Cybernetics. IEEE, 2013:41-44.

[10] Zhao S, Hong J, Zhao $\mathrm{H}$, et al. Research on assembly sequence planning method for largescale assembly based on an integrated assembly model [J]. Proceedings of the Institution of Mechanical Engineers Part B Journal of Engineering Manufacture, 2012, 226(4):733744.

[11] Li Tao. Hull assembly key technology research [J]. New technologies and products, 2016(18):93-94.

[12] Xu W, Li M, Zhang W. The Three-dimensional Digital Factory for Shipbuilding Technology Research [J]. 2016, 70:05003.

[13] Liu G X. Present Situation and Development of Precision Control Technology on Modern Digital Shipbuilding [J]. Ship Engineering, 2011, 33(6):65-68.

[14] Lee D M, Kim S Y, Moon B Y. Development of Ship-Building Assembly System for Ship's Blocks Using 3D Measurements System[J]. Applied Mechanics \& Materials, 2014, 635637:621-624.

[15] Lee H D, Son M J, Oh M J, et al. Development of a simple model for batch and boundary information updation for a similar ship's block model [J]. Science China Information Sciences, 2012, 55(5):1019-1031.

[16] Cristinel ILIE, Daniel COMEAGA, Octavian DONTU, Adrian NEDELCU, Gheorghe GHEORGHE. MODELING, SIMULATION AND VALIDATION. Romanian Review Precision Mechanics, Optics and Mechatronics.2013, 43:119-125. 